\title{
Emotional Changes and Protective Factors of Emotional Workers in the Public and Private Sector
}

\author{
Jongha Lee ${ }^{1}$, Changsu Han ${ }^{1}$, Young-Hoon Ko', June Kang ${ }^{2}$, \\ Youngmi Byun ${ }^{3}$, Yeonghae Son ${ }^{3}$, and Ho-Kyoung Yoon ${ }^{1 凶}$ \\ 1'Department of Psychiatry, Korea University Ansan Hospital, Ansan, Republic of Korea \\ ${ }^{2}$ Department of Brain and Cognitive Engineering, Korea University, Seoul, Republic of Korea \\ ${ }^{3}$ Ansan Community Mental Health Center, Ansan, Republic of Korea
}

\begin{abstract}
Objective Emotional labor is known to be a risk factor for emotional distress. This study aimed to evaluate specific stressors according to the type of occupation and identify protective and adverse factors.

Methods We recruited 349 workers engaged in emotional labor in a suburban city. They were assessed using scales regarding emotional status, job stress, resilience, and job satisfaction. Correlation and regression analyses were performed to evaluate their emotional state according to their stress level. A mediation model using structural equation modeling was utilized to identify the mediating effects of resilience and workplace satisfaction.

Results The correlation analysis indicated that the level of workplace stress was statistically correlated with depressed mood and anxiety and showed a significant inverse correlation with individuals' resilience and job satisfaction. According to the regression analysis, in private institution workers, "emotional disharmony and hurt" had a statistically significant negative effect on their emotional state, and in public institution workers, "emotional demands and regulation" were prominent. Resilience partially mediated the relationship between emotional stress and anxiety/depressive symptoms.
\end{abstract}

Conclusion Our findings indicate that the causes of stress differed according to the working environment. Preventive strategies such as resilience training and relieving stress on individual factors are needed to promote mental health.

Psychiatry Investig 2020;17(7):645-653

Key Words Emotional labor, Job stress, Resilience, Depressive mood, Anxiety.

\section{INTRODUCTION}

"Emotional labor" refers to work where individuals have to do their duty irrespective of the emotions they actually feel; these workers are called "emotional laborers." Emotional laborers consist mainly of service workers, sales workers, and public institution workers. In a broad sense, the term may include all people who come into direct contact with other people while working and are required to control their emotions in this process to adhere to the rules of their organization. ${ }^{1}$ Emotional laborers often interact with customers during work

Received: December 12, 2019 Revised: February 26, 2020

Accepted: March 24, 2020

$\triangle$ Correspondence: Ho-Kyoung Yoon, MD, PhD

Department of Psychiatry, Korea University Ansan Hospital, 123 Jeokguem-ro, Danwon-gu, Ansan 15355, Republic of Korea

Tel: +82-31-412-5140, Fax: +82-31-412-5132, E-mail: hkhkgogo@korea.ac.kr (a) This is an Open Access article distributed under the terms of the Creative Commons Attribution Non-Commercial License (https://creativecommons.org/licenses/by$\mathrm{nc} / 4.0$ ) which permits unrestricted non-commercial use, distribution, and reproduction in any medium, provided the original work is properly cited. and have to pay attention to their customer's feelings regardless of their own emotions. It is known that there is a high risk of emotional distress in such work due to the negative emotional expressions of other people. ${ }^{2-5}$ Emotional laborers are known to experience relatively more stress than other occupational groups. ${ }^{6,7}$ In addition, it has been found that temporary employees who are at high risk of unemployment are insufficiently protected against unfair treatment. ${ }^{8}$ This kind of emotional suppression can increase the risk of depression and anxiety disorders, and emotional trauma can be a risk factor for trauma-related disorders such as post-traumatic stress disorder. ${ }^{2,3,6,9}$ Similarly, salespersons can come under a lot of stress in the process of dealing with the needs and complaints of customers, and their risk of depressive disorders is higher than that of others. ${ }^{4,10}$ Repeated exposure to risk factors and adverse responses may increase the risk of suicide. ${ }^{10}$

Work stress can be affected by both environmental influences and personal characteristics. ${ }^{6}$ Types of jobs, forms of employment, main work content and job security can also af- 
fect workplace stress. The seriousness of work stress varies depending on the type of work, but similar types of emotional laborers may face different types of stress at work depending on their sex. Studies conducted in Denmark reported that job stress increases the risk of anxiety disorders in men and increases the risk of depression in women. ${ }^{11}$ Job satisfaction and personal characteristics act as factors to reduce stress. Health care workers in hospitals are consistently exposed to excessive physical labor burdens and high stress from emotional labor, and reducing their emotional stress is associated with improved quality of life and job satisfaction. ${ }^{5,12-14}$ The higher the job satisfaction, the lower the subjective stress; moreover, the personality and characteristics of an individual may affect their stress response. ${ }^{15}$ Recently, interest in strengthening the resilience of individuals as a strategy for dealing with stress is increasing. ${ }^{13,16}$ Resilience refers to a person's ability to adapt successfully to acute stress, trauma, or more chronic forms of adversity and maintain their psychological well-being. ${ }^{17}$ Strengthening resilience can increase one's ability to overcome stress and is also known as a protective factor against mental illnesses such as depressive and anxiety disorders. ${ }^{16-18}$

There have been several reports of high stress from emotional laborers with certain jobs, such as hospital staff, police officers and firefighters, but studies comparing workers with different jobs are limited to date. ${ }^{12-14,19,20}$ Currently, there are no comparative studies of public and private institution workers. The two groups have different occupational characteristics, and the stress factors of each worker also differ. Public institution workers are guaranteed job security, but individual autonomy tends to be curbed, while private institution workers are not guaranteed stable income. There are also differences in working conditions such as working hours and culture at work. This study aimed to classify emotional laborers as public and private institution workers, and to examine the causes of stress in each group, differences in stress levels, and ways to relieve stress through comparisons between the two groups. This study tests the following hypotheses: 1 ) there are specific stress factors of emotional laborers that depend on the type of work and 2) there are some stress worsening factors and protective factors for emotional laborers. After examining the above hypotheses, we suggest some social and personal solutions to the causes of occupational stress.

\section{METHODS}

\section{Participants}

This study involved workers engaged in emotional labor in Ansan-si, a suburban city of Seoul. They included civil service employees in public institutions, social workers, nursing care workers, childcare teachers, and service workers. This study was conducted for nine months beginning in March 2018 by the Ansan Community Mental Health Center, using measures of emotional state and workplace stress. The survey was conducted on workers engaged in emotional labor at public and private institutions. They received sufficient explanations of the study and those who agreed to it were included in the study. In this study, there were 489 participants; however, 140 participants who did not complete the questionnaire were excluded. In the end, the data of 349 participants were included in the analysis.

\section{Clinical measures}

Sociodemographic information, such as sex, education level, age, working period, employment form, and working hours per week, was collected. Workplaces were classified into public and private institutions, and forms of employment were classified into regular and temporary positions. The main tasks were assessed by dividing them into customer service, staff management, office work, and others.

\section{Korean Emotional Labor Scale}

The Korean Emotional Labor Scale (K-ELS), which was developed by the Korea Occupational Safety and Health Agency, was used to evaluate the actual state of emotional labor. ${ }^{21}$ The K-ELS is composed of five sub-factors: 1) "emotional demands and regulation" (five items), 2) "organizational surveillance and monitoring" (three items), 3) "overload and conflict in customer service," 4) "emotional disharmony and hurt" (five items), and 5) "organization support and protection system" (five items). Each item used a four-point Likert scale ( $1=$ not at all, $2=$ slightly not, $3=$ slightly, $4=$ absolutely) and the "organizational support and protection system" (seven items) consisted of reverse Likert scores (4-3-2-1 score). Regarding reliability, the Cronbach's a value estimated in K-ELS development studies ranged from 0.79 to 0.86 .

\section{Korean Occupational Stress Scale-Short Form}

The Korean Occupational Stress Scale (KOSS) was developed to assess workers' stress in the workplace, and its validity and reliability were confirmed. ${ }^{22}$ The questionnaire consists of 43 items that are measured on a four-point Likert scale. In this study, the KOSS-Short Form (KOSS-SF), which was designed to be easily applied in the field, was used due to the large number of questions in the original. ${ }^{22}$ The sub-items are classified into seven categories: 1) job demands (four items), 2) insufficient job control (four items), 3) occupational system (four items), 4) lack of rewards (three items), 5) job insecurity (two items), 6) interpersonal conflict (three items), and 7) organizational climate (four items). The higher the score, the higher the job stress factor for the 1-2-3-4 scale (1=not at all, 
$2=$ slightly not, $3=$ slightly, $4=$ absolutely), and those with low job stress factors were rated as 4-3-2-1 (1=absolutely, $2=$ slightly, $3=$ slightly not, $4=$ not at all).

\section{Minnesota Satisfaction Questionnaire}

"Job satisfaction" refers to the pleasant and positive emotional state related to an individual's job and experience. High satisfaction with one's occupation is one of the factors preventing burnout in the workplace. ${ }^{23}$ The Minnesota Satisfaction Questionnaire (MSQ) developed by Weiss et al. ${ }^{24}$ is a self-reported measure of job satisfaction. In this study, the MSQ was used to measure job satisfaction. This instrument consists of 20 items, consisting of intrinsic factors (12 items), external factors ( 6 items), and overall factors ( 2 items). Items are rated from 1 (strong dissatisfaction) to 5 (strong satisfaction) and the total scores range from 20 (low level of job satisfaction) to 100 (high level of job satisfaction). The validity of the Korean version was assessed and Cronbach's a was $0.87 . .^{25}$

\section{Korean Resilience Quotient}

Resilience is defined as the ability to overcome adversity in life and return to the pre-stress adaptation level. ${ }^{26}$ Resilience is understood to be influenced by external environmental factors in addition to individual innate factors and serves as a mediator in overcoming stressful situations. In this study, the Korean Resilience Quotient-53 (KRQ) was used to assess individual resilience. ${ }^{27}$ The KRQ is a translation and modification of the Resilience Quotient Test developed by Reivich and Shatte for adults. ${ }^{28}$ It is composed of a total of 53 items and consists of 9 sub-factors: 1) emotion control, 2) impulse control, 3) causal analysis, 4) communication, 5) empathy, 6) selfextension, 7) self-optimism, 8) life satisfaction, and 9) gratitude attitude. The nine sub-factors consist of three high order secondary factors: 1) self-regulation, 2) interpersonal skills, and 3) affirmation. They were measured using Likert scales ranging from 0 to 5 , with higher scores indicating higher resilience.

\section{Patient Health Questionnaire-9}

The Korean version of the Patient Health Questionnaire-9 (PHQ-9), which was developed by Spitzer et al. ${ }^{29}$ and translated and validated by Han et al., ${ }^{30}$ was used to evaluate depression. The PHQ-9 scale consists of nine items measured on a four-point Likert scale. Depression was classified into four categories according to the total score: between 0 and 4 was "not depressed"; between 5 and 9 was "mild depression"; between 10 and 19 was "moderate depression"; and between 20 and 27 was classified as "severe depression."

\section{Generalized Anxiety Disorder-7}

The Generalized Anxiety Disorder-7 (GAD-7) consists of a seven-item self-report questionnaire. Items on the GAD-7 are rated on a four-point Likert scale and are related to anxiety symptoms. ${ }^{31}$ Total scores range from 0 to 21 , and a high total score means a high level of anxiety. Seo et al..$^{32}$ translated and validated the Korean version of the GAD-7 and in this study, the internal consistency was 0.915 ; the sensitivity and specificity were 0.89 and 0.82 , respectively. ${ }^{32}$

\section{Statistical analysis}

Between-group differences were assessed using chi-square tests and Student t-tests for sociodemographic data, K-ELS, KOSS-SF, MSQ, KRQ53, PHQ-9, and GAD-7. A Spearman's correlation test was used to investigate the correlation between job stress (KOSS-SF, K-ELS), individual internal factors (MSQ, KRQ), and emotional state (PHQ-9, GAD-7). We tested the mediation model using structural equation modeling (SEM). We performed the mediation analysis with KRQ and MSQ scores as mediating variables, the ELS score as an independent variable, and the PHQ-9 and GAD-t scores as dependent variables to confirm the mediating effect of resilience and job satisfaction. The SEM analyses were performed using AMOS version 24 . All other statistical analyses were performed using the Statistical Package for the Social Sciences 22.0 (SPSS IBM Corp., Armonk, NY, USA).

\section{Ethics statement}

The study protocol was approved by the Institutional Review Board of the Korea University Medical Center, Ansan Hospital, Gyeonggi-do, Korea (No. 2019AS0199). All participants provided written informed consent.

\section{RESULTS}

\section{Sociodemographic characteristics}

The sociodemographic characteristics of the participants are shown in Table 1. A total of 349 participants were enrolled in this study (male: 46, female: 303). Among the 349 participants, 179 people $(51.3 \%)$ were public institution workers. The majority of participants were in their 30s (121 participants, $34.7 \%), 100$ were in their 20s (28.7\%), 85 in their 40s (24.4\%), 35 in their 50s (10.0\%), and eight in their 60s (2.3\%). Their highest academic achievement was as follows, in order from most common to least common: university graduate $(n=164$, $47 \%)$, high school graduate $(n=75,21.5 \%)$, college graduate $(n=67,19.2 \%)$, and graduate school graduate $(n=43,12.3 \%)$. The working period of the majority was $5-10$ years $(n=91$, $26.1 \%$ ) and the average weekly working hours was 33.15 hours (SD: 14.65). Customer service was found to be the main task 
Table 1. Demographic and descriptive data

\begin{tabular}{|c|c|c|c|c|}
\hline Variables & $\begin{array}{l}\text { Public institution } \\
\text { workers }(\mathrm{N}=179)\end{array}$ & $\begin{array}{l}\text { Private institution workers } \\
\qquad(\mathrm{N}=170)\end{array}$ & $\chi^{2}$ or $t$ & $\mathrm{p}$ \\
\hline Sex, female, N (\%) & $143(79.9)$ & $160(94.1)$ & 15.428 & $<0.001$ \\
\hline Age, N (\%) & & & 15.382 & 0.004 \\
\hline 20-30 years & $50(27.9)$ & $50(29.4)$ & & \\
\hline $30-40$ years & $77(43.0)$ & $44(25.9)$ & & \\
\hline $40-50$ years & $35(19.6)$ & $50(29.4)$ & & \\
\hline $50-60$ years & $12(6.7)$ & $23(13.5)$ & & \\
\hline Above 60 years & $5(2.8)$ & $3(1.8)$ & & \\
\hline Education level, N (\%) & & & 84.870 & $<0.001$ \\
\hline High school graduate & $10(5.6)$ & $65(38.2)$ & & \\
\hline College graduate & $22(12.3)$ & $45(26.5)$ & & \\
\hline University graduate & $115(64.2)$ & $49(28.8)$ & & \\
\hline Graduate school graduate & $32(17.9)$ & $11(6.5)$ & & \\
\hline Working period, $\mathrm{N}(\%)$ & & & 11.187 & 0.025 \\
\hline Less than 1 year & $15(8.4)$ & $29(17.2)$ & & \\
\hline $1-2$ years & $40(22.3)$ & $30(17.8)$ & & \\
\hline $3-5$ years & $47(26.3)$ & $39(23.1)$ & & \\
\hline $5-10$ years & $41(22.9)$ & $50(29.6)$ & & \\
\hline More than 10 years & $36(20.1)$ & $21(12.4)$ & & \\
\hline Employment form & & & 21.542 & $<0.001$ \\
\hline Regular & $129(72.1)$ & $80(47.1)$ & & \\
\hline Temporary & $47(26.2)$ & $84(49.4)$ & & \\
\hline No response & $3(1.7)$ & $6(3.5)$ & & \\
\hline Working time per week, hours (mean \pm SD) & $35.44 \pm 13.21$ & $30.62 \pm 15.73$ & -3.068 & 0.003 \\
\hline KOSS-SF total $($ mean $\pm S D)$ & $57.10 \pm 6.99$ & $58.39 \pm 7.15$ & 1.709 & 0.088 \\
\hline Job demands & $11.07 \pm 2.00$ & $11.46 \pm 2.02$ & 1.846 & 0.660 \\
\hline Insufficient job control & $9.56 \pm 1.76$ & $10.39 \pm 2.02$ & 4.052 & $<0.001$ \\
\hline Occupational system & $9.70 \pm 1.88$ & $9.66 \pm 1.92$ & -0.165 & 0.869 \\
\hline Lack of rewards & $7.48 \pm 1.50$ & $7.71 \pm 1.71$ & 1.310 & 0.193 \\
\hline Job insecurity & $4.16 \pm 1.40$ & $4.33 \pm 1.49$ & 1.079 & 0.281 \\
\hline Interpersonal conflict & $6.28 \pm 1.29$ & $6.48 \pm 1.61$ & 1.294 & 0.001 \\
\hline Organizational climate & $8.85 \pm 2.06$ & $8.36 \pm 2.14$ & -2.182 & 0.030 \\
\hline K-ELS total (mean \pm SD) & $63.06 \pm 8.64$ & $66.86 \pm 9.67$ & 3.879 & $<0.001$ \\
\hline Emotional demands and regulations & $15.57 \pm 2.12$ & $16.09 \pm 2.56$ & 2.058 & 0.040 \\
\hline Organizational surveillance and monitoring & $6.40 \pm 1.81$ & $7.66 \pm 2.08$ & 6.044 & $<0.001$ \\
\hline Overload and conflict in customer service & $8.77 \pm 2.64$ & $9.12 \pm 2.06$ & 1.596 & 0.111 \\
\hline Emotional disharmony and hurt & $15.53 \pm 3.70$ & $17.08 \pm 3.79$ & 3.867 & $<0.001$ \\
\hline Organizational support and protection system & $16.79 \pm 2.71$ & $16.91 \pm 3.22$ & 0.371 & 0.711 \\
\hline KRQ total (mean $\pm S D)$ & $183.73 \pm 19.53$ & $179.26 \pm 20.66$ & -2.079 & 0.038 \\
\hline Self-regulation & $61.53 \pm 8.04$ & $59.47 \pm 7.57$ & -2.455 & 0.015 \\
\hline Interpersonal skills & $63.50 \pm 6.80$ & $62.91 \pm 7.47$ & -0.782 & 0.435 \\
\hline Affirmation & $58.70 \pm 8.09$ & $56.88 \pm 9.27$ & -1.958 & 0.051 \\
\hline MSQ total $($ mean $\pm S D)$ & $65.30 \pm 8.85$ & $62.72 \pm 9.23$ & -2.671 & 0.008 \\
\hline Intrinsic factors & $40.19 \pm 5.22$ & $38.44 \pm 6.00$ & -2.909 & 0.004 \\
\hline External factors & $18.15 \pm 3.34$ & $17.48 \pm 3.34$ & -1.854 & 0.065 \\
\hline Overall factors & $6.97 \pm 1.28$ & $6.79 \pm 1.46$ & -1.171 & 0.242 \\
\hline GAD-7 (mean \pm SD) & $3.55 \pm 3.75$ & $4.26 \pm 4.22$ & 1.650 & 0.100 \\
\hline PHQ-9 (mean \pm SD) & $5.17 \pm 4.37$ & $6.70 \pm 5.37$ & 2.906 & 0.004 \\
\hline
\end{tabular}

SD: standard deviation, KOSS-SF: Korean Occupational Stress Scale-Short Form, K-ELS: Korean Emotional Labor Scale, KRQ: Korean Resilience Quotient, MSQ: Minnesota Satisfaction Questionnaire, GAD-7: Generalized Anxiety Disorder-7, PHQ-9: Patient Health Questionnaire-9 
among all participants ( $\mathrm{n}=266,76.2 \%)$.

\section{Analyses between different groups (private institution versus public institution and regular versus temporary)}

There were statistically significant differences in sex, age, educational level, working period and employment form when comparing private and public institution workers. The proportion of women was higher in private institutions. In public institutions, the ratio of highly educated and full-time workers was higher, and working hours were also found to be longer. In both groups, the main task was customer service (public, $\mathrm{n}=123,68.7 \%$, private, $\mathrm{n}=143,87.1 \%$ ). Private institution workers showed a statistically higher level of depressive mood than public institution workers; however, the difference in anxiety level difference between the two groups was not significant (Table 1). Private institution workers showed statistically significantly higher levels of stress, in the areas of "organizational surveillance and monitoring," "emotional disharmony and hurt," and "insufficient job control." "Resilience" and "workplace satisfaction" were significantly higher in the public institution workers. When comparing regular employees with temporary ones, there was no statistically significant difference in emotional states such as depression and anxiety. On the job stress test, "job insecurity" (KOSS-SF) was higher in temporary employees $(\mathrm{t}=-3.27, \mathrm{p}=0.001)$ and "job demand" (KOSS-SF) was higher in regular employees $(\mathrm{t}=3.11, \mathrm{p}=0.002)$.

\section{Correlations between job stress, resilience, job satisfaction, and emotional state}

Job stress was positively correlated with depressive moods and anxiety, and this was statistically significant in the correlation analysis including all participants. On the K-ELS, "emotional disharmony and hurt" showed a relatively high correlation with depressive $\operatorname{mood}(\mathrm{r}=0.453, \mathrm{p}<0.001)$. In contrast, job satisfaction and individual resilience were inversely correlated with depressive mood and anxiety. "Intrinsic factors" from the MSQ $(r=-0.369, p<0.001)$, "self-regulation" $(r=-0.434$, $\mathrm{p}<0.001)$, and "affirmation" $(\mathrm{r}=-0.535, \mathrm{p}<0.001)$ showed a rel- atively high inverse correlation with depressive mood. Table 2 shows the correlations among the total scores of the variables in all participants (Table 2).

\section{Multiple regression analyses of private and public institution emotional laborers}

To assess the factors influencing the emotional state of private and public institution workers, a stepwise multiple regression analysis was performed for each group using the scores of the sub-items of the K-ELS, KOSS-SF, MSQ, and $\mathrm{KRQ}$ as independent variables and the total emotional scale scores (PHQ-9 and GAD-7) as dependent variables. In private institution workers "emotional disharmony and hurt" $(\beta=$ $0.330, p<0.001)$ from the K-ELS and "life satisfaction" $(\beta=-0.300$, $\mathrm{p}<0.001)$ and "emotion control" $(\beta=-0.232, \mathrm{p}=0.001)$ from the KRQ were statistically significantly related to the total score of the PHQ-9. "Self-optimism" $(\beta=-0.188, p<0.05)$ from the KRQ was statistically significant with the total score of the GAD-7. In public institution workers, "emotional demands and regulations" ( $\beta=0.179, \mathrm{p}=0.003)$ from the K-ELS and "emotion control" ( $\beta=-0.265, p<0.001)$ and "life satisfaction" $(\beta=$ $-0.398, \mathrm{p}<0.001)$ from the KRQ were statistically significantly related to the total score of the PHQ-9. The other results are shown in Table 3.

\section{Mediation of relationship between emotional labor stress and anxiety and depressive symptoms through resilience in all participants}

Figure 1 shows the model of the relationship between emotional stress and current depressive and anxiety symptoms, as mediated by individual resilience and job satisfaction. $\chi^{2}$, root mean square error of approximation (RMSEA), comparative fit index (CFI), and goodness-of-fit index (GFI) were used to evaluate goodness of fit. The fit indices for this model were $\chi^{2}=634.372$ (degrees of freedom $=144, \mathrm{p}<0.001$ ), $\mathrm{CFI}=0.830$, GFI $=0.830$, and RMSEA $=0.099$. The direct path from emotional stress to all of the variables and the direct path from resilience to all of the variables were statistically significant. The standardized path coefficients were as follows: the path from

Table 2. Correlation coefficients between variables in all participants

\begin{tabular}{lcccccc}
\hline & KOSS-SF & K-ELS & KRQ & MSQ & GAD-7 & PHQ-9 \\
\hline KOSS-SF & 1 & & & & & \\
K-ELS & $0.563^{*}$ & 1 & & & & \\
KRQ & $-0.385^{*}$ & $-0.323^{*}$ & 1 & & & \\
MSQ & $-0.714^{*}$ & $-0.514^{*}$ & $0.446^{*}$ & 1 & & \\
GAD-7 & $0.240^{*}$ & $0.347^{*}$ & $-0.476^{*}$ & $-0.280^{*}$ & 1 & \\
PHQ-9 & $0.288^{*}$ & $0.395^{*}$ & $-0.488^{*}$ & $-0.339^{*}$ & $0.778^{*}$ & 1 \\
\hline
\end{tabular}

${ }^{*} \mathrm{p}<0.001$. KOSS-SF: Korean Occupational Stress Scale-Short Form, K-ELS: Korean Emotional Labor Scale, KRQ: Korean Resilience Quotient, MSQ: Minnesota Satisfaction Questionnaire, GAD-7: Generalized Anxiety Disorder-7, PHQ-9: Patient Health Questionnaire-9 
emotional stress to resilience was $\beta=-0.362, \mathrm{p}=0.003$ and to job satisfaction was $\beta=-0.333$, $p=0.004$; the path from emotional stress to anxiety was $\beta=0.274, p=0.005$ and to depressive symptoms was $\beta=0.142, p=0.017$; and the path from resilience to anxiety was $\beta=-0.449, \mathrm{p}<0.001$ and to depressive symptoms was $\beta=-0.115, p=0.019$. The direct path from job satisfaction to anxiety and depressive symptoms was not statistically significant. To examine the statistical significance of the indirect effect of the model, we performed a bootstrap analysis. Table 4 summarizes the paths and significance of indirect effects. Resilience was statistically significant in this model, but job satisfaction was not significant. This result suggests that resilience partially mediated the relationship between emotional stress and anxiety/depressive symptoms, while job satisfaction did not mediate it. Therefore, resilience was considered to be a protective factor that reduces depression and anxiety caused by workplace stress.

\section{DISCUSSION}

Previous studies have investigated the relationship between stress and mental illness in the workplace. In particular, workers who are engaged in emotional labor and have to respond

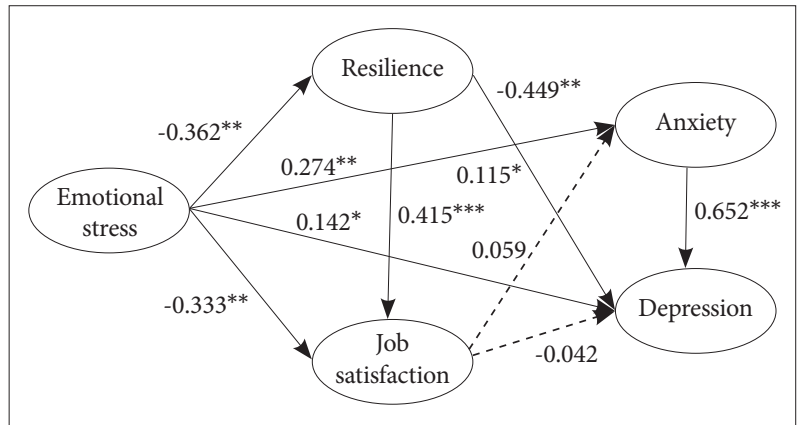

Figure 1. Mediation of relationship between emotional stress and anxiety and depressive symptoms through resilience and job satisfaction in all participants. Solid arrow: $p<0.05$, Dotted arrow: statistically not significant, ${ }^{*} p<0.05,{ }^{* *} p<0.01,{ }^{* *} p<0.001$.

Table 3. Factors affecting emotional status of workers

\begin{tabular}{|c|c|c|c|c|c|c|c|c|}
\hline \multirow{2}{*}{ Variables } & \multicolumn{4}{|c|}{ PHQ-9 } & \multicolumn{4}{|c|}{ GAD-7 } \\
\hline & $\beta \pm S E$ & $\beta$ & $\mathrm{t}$ & $\mathrm{p}$ & $\beta \pm S E$ & $\beta$ & $\mathrm{t}$ & $\mathrm{p}$ \\
\hline \multicolumn{9}{|l|}{ Private institution workers } \\
\hline K-ELS_Emotional disharmony and hurt & $0.468 \pm 0.092$ & 0.330 & 5.058 & $<0.001$ & $0.236 \pm 0.078$ & -0.240 & -3.132 & 0.003 \\
\hline KRQ_Life satisfaction & $-0.426 \pm 0.091$ & -0.300 & -4.693 & $<0.001$ & $-0.173 \pm 0.079$ & -0.155 & -2.194 & 0.030 \\
\hline KRQ_Emotion control & $-0.400 \pm 0.115$ & -0.232 & -3.485 & 0.001 & $-0.326 \pm 0.104$ & -0.240 & -3.132 & 0.002 \\
\hline KRQ_Self-optimism & & n.s. & & & $-0.225 \pm 0.096$ & -0.188 & -2.336 & 0.021 \\
\hline \multicolumn{9}{|c|}{ PHQ-9: $\mathrm{R}^{2}=0.401$ Adjusted $\mathrm{R}^{2}=0.390 \mathrm{~F}=39.054 \mathrm{p}<0.001, \mathrm{GAD}-7: \mathrm{R}^{2}=0.342$ Adjusted $\mathrm{R}^{2}=0.326 \mathrm{~F}=21.451 \mathrm{p}<0.001$} \\
\hline \multicolumn{9}{|l|}{ Public institution workers } \\
\hline K-ELS_Emotional demands and regulations & $0.371 \pm 0.124$ & 0.179 & 2.983 & 0.003 & $0.259 \pm 0.111$ & 0.146 & 2.328 & 0.021 \\
\hline KRQ_Emotion control & $-0.334 \pm 0.085$ & -0.265 & -3.946 & $<0.001$ & $-0.331 \pm 0.084$ & -0.307 & -3.931 & $<0.001$ \\
\hline KRQ_Life satisfaction & $-0.497 \pm 0.084$ & -0.398 & -5.940 & $<0.001$ & $-0.235 \pm 0.076$ & -0.220 & -3.107 & 0.002 \\
\hline KRQ_Impulse control & & n.s. & & & $-0.172 \pm 0.086$ & -0.147 & -1.998 & 0.047 \\
\hline \multicolumn{9}{|c|}{ PHQ-9: $\mathrm{R}^{2}=0.393$, Adjusted $\mathrm{R}^{2}=0.383, \mathrm{~F}=37.568, \mathrm{p}<0.001 ; \mathrm{GAD}-7: \mathrm{R}^{2}=0.343$, Adjusted $\mathrm{R}^{2}=0.328, \mathrm{~F}=22.607, \mathrm{p}<0.001$} \\
\hline \multicolumn{9}{|c|}{$\begin{array}{l}\text { K-ELS: Korean Emotional Labor Scale, KRQ: Korean Resilience Quotient, GAD-7: Generalized Anxiety Disorder-7, PHQ-9: Patient Health } \\
\text { Questionnaire-9, B: unstandardized regression coefficient, SE: standard error, } \beta \text { : standardized regression coefficient, n.s.=not significant }\end{array}$} \\
\hline \multirow{2}{*}{\multicolumn{2}{|c|}{ Path }} & \multirow[t]{2}{*}{ Estimate } & & \multicolumn{3}{|c|}{$\begin{array}{l}95 \% \text { bias-corrected } \\
\text { confidence intervals }\end{array}$} & \multirow{2}{*}{\multicolumn{2}{|c|}{$\mathrm{p}$ value }} \\
\hline & & & & Lower & Upp & & & \\
\hline \multicolumn{2}{|l|}{ Emotional stress $\rightarrow$ resilience $\rightarrow$ anxiety } & \multicolumn{2}{|l|}{1.164} & \multicolumn{3}{|l|}{0.586} & \multicolumn{2}{|c|}{0.001} \\
\hline \multicolumn{2}{|l|}{ Emotional stress $\rightarrow$ resilience $\rightarrow$ depression } & \multicolumn{2}{|l|}{0.370} & \multicolumn{3}{|c|}{0.062} & \multicolumn{2}{|c|}{0.016} \\
\hline \multicolumn{2}{|l|}{ Emotional stress $\rightarrow$ resilience $\rightarrow$ anxiety $\rightarrow$ depression } & \multicolumn{2}{|l|}{0.939} & \multicolumn{3}{|l|}{0.463} & \multicolumn{2}{|c|}{0.001} \\
\hline \multicolumn{2}{|c|}{ Emotional stress $\rightarrow$ resilience $\rightarrow$ job satisfaction $\rightarrow$ anxiety } & \multicolumn{2}{|l|}{-0.063} & \multicolumn{3}{|l|}{-0.336} & \multicolumn{2}{|c|}{ n.s. } \\
\hline \multicolumn{2}{|l|}{ Emotional stress $\rightarrow$ job satisfaction $\rightarrow$ anxiety } & \multicolumn{2}{|l|}{-0.141} & \multicolumn{3}{|l|}{-0.618} & \multicolumn{2}{|c|}{ n.s. } \\
\hline \multicolumn{2}{|l|}{ Emotional stress $\rightarrow$ job satisfaction $\rightarrow$ depression } & -0.141 & & -0.618 & 0.17 & & n.s. & \\
\hline
\end{tabular}

n.s.: not significant 
to customers are known to face higher stress than workers in other occupations. ${ }^{4,67,10,33}$ There is a high risk of mental illness due to the suppression of their emotions, instability of their income, and need to behave contrarily to their feelings in unreasonable situations.

Similar to previous studies, ${ }^{2,19,33}$ the results of this study showed that the higher the workplace stress, the lower the job satisfaction and resilience, and the higher the depression and anxiety. A study of temporary employees reported that job insecurity and a lack of rewards were associated with poor mental health as a cause of stress. ${ }^{34}$ Temporary employees have a relatively high level of stress because they are not guaranteed a retirement age and are at risk of losing their jobs suddenly throughout their carriers. It is necessary to guarantee contract work for a certain period of time and introduce social institutional measures against unfair dismissal. Similarly, in this study, stress related to job insecurity was significantly higher in temporary employees, but there were no statistically significant differences in depression and anxiety when temporary employees were compared with regular employees. This result may have been affected by sex ratio. Aletaris ${ }^{35}$ found that female workers had relatively higher job satisfaction than male workers in a study of temporary employees in Australia. Approximately $87 \%$ of participants in this study were women, which may have influenced the results.

Private institution workers complained of higher levels of depressive symptoms and anxiety than public institution workers, and depressive symptoms were statistically significantly higher in private institution workers. Private institution workers experienced particularly high levels of stress in the areas of "organizational surveillance and monitoring," "emotional disharmony and hurt," and "insufficient job control." There was also a statistically significant difference in "resilience" and "workplace satisfaction," which were considered protective factors against anxiety and depression, and were higher in public institution workers. There was no difference in the external factors of job satisfaction, but the public institution workers' satisfaction was higher when considering internal factors. In the case of public institution workers, their salaries, working hours, and work contents are relatively constant, and their job security is guaranteed. Therefore, it is thought that public institution workers' stress is lower than that of private institution workers in consideration of workplace variables. As shown in Table 2, resilience was highly correlated with job satisfaction. The relatively high level of resilience of the public institution workers group was thought to act as a factor that helped them overcome job stress and reinforced positive aspects.

Through a multiple regression analysis, the protective and risk factors of public institution workers and private institution workers were analyzed. In the case of private institution workers, emotional disharmony caused by problems with customers appeared to aggravate their depressive symptoms and anxiety, and skills related to life satisfaction, emotion control, and self-optimism were evaluated as protective factors. On the other hand, in public institution workers, individual emotional demands and regulations were risk factors, and skills related to emotion control, impulse control, and life satisfaction were evaluated as protective factors. This result confirms the hypothesis that the type of stress and factors that can alleviate stress differ by employment type. Private institution workers often have to react contrary to their feelings because their attitudes toward their customers can affect their income. In addition, those who work in private workplaces are at a high risk of getting too much feedback from their employers about their attitudes toward customers, and this phenomenon is thought to be cause of a high level of stress. Furthermore, in a social atmosphere where the buyer's position is considered important, as in the case of black consumers, there are many cases in which workers have to act contrary to their feelings, even if they are wronged. Private institution workers were found to be significantly affected by the external aspects of work such as life satisfaction and self-optimism as solutions to stress. They were thought of as attitudes to gain emotional peace in other places rather than addressing stress at work. In order to relieve the stress of private institution workers, institutions should develop interventions for unfair situations that result from conflicts with customers; workers should also try to develop ways to reduce their stress on their own after work. On the other hand, the risk factors were different for public institution workers. In public workplaces, there is a tendency to proceed according to the guidelines, as policy is set internally to cope with problems during the customer response process. Public institution workers are less likely to behave contrary to their feelings, but there are cases where they need to suppress their negative emotions. Especially in public institutions that are sensitive to people's complaints, it may be necessary to suppress emotions. In particular, public institution workers who have lower positions or frequent face-to-face meetings can be at higher risk. This can progress to negative emotional states such as depression and anxiety. In public institution workers, factors evaluated as protective factors included emotion control and impulse suppression. The higher this kind of resilience, the lower the emotional consumption and perceived stress. Depressive symptoms and anxiety may worsen if the difficulty in controlling emotions persists. Similar stress events affect individuals to different degrees. The more they try to control their feelings, the less they can relieve their stress and prevent mental illness. Therefore, we suggest that methods such as emotional control training and meditation be used to help public institution workers. 
High stress was associated with depression and anxiety, and resilience was identified as a protective factor. ${ }^{26,36}$ In addition, resilience acted as a factor that increased work satisfaction. Those with high resilience experience less depression and anxiety and lead more positive lives ${ }^{36}$ Self-regulation, interpersonal skills, and positivity in stressful situations and negative emotional states can help people recover and maintain a healthy mental state. Resilience is known to be a complex combination of innate and environmental factors. ${ }^{26}$ and research on the factors that contribute to it is ongoing. Childhood attachment to parents, a stable growth process, and good relationships with those around have a positive effect on resilience. Resilience can be improved through practice. Resilience training methods based on cognitive therapy, behavioral therapy, and emotional control training have been proposed. ${ }^{37,38}$ As a result of previous studies, improvements in negative emotions such as stress and anxiety were suggested to increase quality of life, life satisfaction, and optimism. ${ }^{38,39}$ Resilience can be improved through training and is important especially for those who are vulnerable to stress. Individualized resilience training is required for stress management and to prevent mental illnesses such as depression and anxiety.

This study has some limitations. There are statistical differences between public institution workers and private institution workers regarding the sex ratio, age, educational attainment, working period, and weekly working hours; these results were judged to be a reflection of reality. In the case of emotional laborers, the proportion of women is relatively high, especially in areas such as nursing and childcare. In terms of education, public institution workers show higher educational attainment than private institution workers. This is in line with the desire to pursue public work among highly educated populations, rather than due to a bias in the research participants. The statistical differences in the sociodemographic variables in this study are considered to show the characteristics of public and private institution workers, and they may possibly have affected the results of this study. The percentage of women working in private institutions was statistically significantly high, and the overall depression score was also high. Compared to men, workplace stress has been found to affect the severity of depression in women, and the sex ratio may have affected the results of this study. ${ }^{11,35}$ The self-regulation ability of public workers is statistically significantly high, which is thought to have reduced depression and workplace stress. There is a possibility that personal characteristics such as self-regulation ability, academic achievement, resilience and gender may have affected employment. To overcome these limitations, a study comparing both groups with similar sociodemographic information is required. Another limitation is that we did not ask about the kinds of jobs or type of work schedule such as day work, and shift work; this might have affected job satisfaction. ${ }^{40}$

In this study, we identified the stress protection and risk factors of workers engaged in emotional labor in public and private institutions. The severity and risk factors of stress differed depending on the employment form and working environment. Workplace stress was higher for workers in private institutions, and job satisfaction and resilience were higher for workers in public institutions. The risk factor for workers at private institutions was "emotional disharmony and hurt", while the risk factor for workers in public institutions was "emotional demands and regulations." To reduce the stress of workers engaged in emotional labor, not only individual efforts but also changes in social systems and perceptions are needed.

\section{Acknowledgments}

The study was supported by National Research Fund (NRF-2017M3C7 A1041825), Republic of Korea.

\section{Conflicts of Interest}

The authors have no potential conflicts of interest to disclose.

\section{Author Contributions}

Conceptualization: Ho-Kyoung Yoon. Data curation: Ho-Kyoung Yoon, Youngmi Byun. Formal analysis: Jongha Lee, June Kang. Investigation: HoKyoung Yoon. Methodology: Ho-Kyoung Yoon, Young-Hoon Ko, Jongha Lee. Project administration: Ho-Kyoung Yoon. Resources: Ho-Kyoung Yoon, Youngmi Byun, Yeonghae Son. Software: Ho-Kyoung Yoon. Supervision: Ho-Kyoung Yoon. Validation: Ho-Kyoung Yoon, Changsu Han, Jongha Lee. Visualization: Jongha Lee. Writing_original draft: Jongha Lee. Writingreview \& editing: Jongha Lee, Young-Hoon Ko, Changsu Han, Ho-Kyoung Yoon.

\section{ORCID iDs}

$\begin{array}{ll}\text { Jongha Lee } & \text { https://orcid.org/0000-0003-0824-8564 } \\ \text { Changsu Han } & \text { https://orcid.org/0000-0002-4021-8907 } \\ \text { Young-Hoon Ko } & \text { https://orcid.org/0000-0002-5352-2158 } \\ \text { June Kang } & \text { https://orcid.org/0000-0003-3625-0856 } \\ \text { Youngmi Byun } & \text { https://orcid.org/0000-0002-7092-7114 } \\ \text { Yeonghae Son } & \text { https://orcid.org/0000-0001-7447-4477 } \\ \text { Ho-Kyoung Yoon } & \text { https://orcid.org/0000-0002-3302-0660 }\end{array}$

\section{REFERENCES}

1. Grandey AA. Emotion regulation in the workplace: a new way to conceptualize emotional labor. J Occup Health Psychol 2000;5:95-110.

2. Cho JJ, Kim JY, Chang SJ, Fiedler N, Koh SB, Crabtree BF, et al. Occupational stress and depression in Korean employees. Int Arch Occup Environ Health 2008;82:47-57.

3. Hochschild AR. The Managed Heart: Commercialization of Human Feeling. CA: University of California Press; 2012.

4. Han SL, Shim HS, Choi WJ. The effect of emotional labor of college administrative service workers on job attitudes: mediating effect of emotional labor on trust and organizational commitment. Front Psychol 2018; 9:2473.

5. de Castro AB. Emotional vs. physical labor. Am J Nurs 2004;104:120.

6. Nieuwenhuijsen K, Bruinvels D, Frings-Dresen M. Psychosocial work environment and stress-related disorders, a systematic review. Occup Med 2010;60:277-286.

7. Brotheridge CM, Grandey AA. Emotional labor and burnout: comparing two perspectives of "people work." J Vocat Behav 2002;60:17-39. 
8. Wang J, Lesage A, Schmitz N, Drapeau A. The relationship between work stress and mental disorders in men and women: findings from a population-based study. J Epidemiol Community Health 2008;62:42-47.

9. Lee CW, Jeon S, Kim J, Seok BJ, Kim SJ. Depression and anxiety associated with insomnia and recent stressful life events. Chronobiol Med 2019; 1:121-125.

10. Yoon JH, Jeung D, Chang SJ. Does high emotional demand with low job control relate to suicidal ideation among service and sales workers in Korea? J Korean Med Sci 2016;31:1042-1048.

11. Wieclaw J, Agerbo E, Mortensen PB, Burr H, Tuchsen F, Bonde JP. Psychosocial working conditions and the risk of depression and anxiety disorders in the Danish workforce. BMC Public Health 2008;8:280.

12. Katayama H. [Relationship between emotional labor and job-related stress among hospital nurses]. Nihon Eiseigaku Zasshi 2010;65:524-529.

13. Delgado C, Upton D, Ranse K, Furness T, Foster K. Nurses' resilience and the emotional labour of nursing work: an integrative review of empirical literature. Int J Nurs Stud 2017;70:71-88.

14. Han KM, Shin C, Yoon HK, Ko YH, Kim YK, Han C. Emotional labor and depressive mood in service and sales workers: interactions with gender and job autonomy. Psychiatry Res 2018;267:490-498.

15. Park YN, Yoon SU. Health promotion behavior of some local dental hygienist convergence impact on emotional labor, quality of life, job satisfaction. J Korea Converg Soc 2016;7:25-33.

16. Moon Y, Shin SY. Moderating Effects of resilience on the relationship between emotional labor and burnout in care workers. J Gerontol Nurs 2018;44:30-39

17. Charney DS. Psychobiological mechanisms of resilience and vulnerability: implications for successful adaptation to extreme stress. Am J Psychiatry 2004;161:195-216.

18. Rutter M. Psychosocial resilience and protective mechanisms. Am J Orthopsychiatry 1987;57:316-331.

19. Lambert EG, Qureshi H, Frank J, Klahm C, Smith B. Job stress, job involvement, job satisfaction, and organizational commitment and their associations with job burnout among Indian police officers: a research note. J Police Crim Psychol 2018;33:85-99.

20. Wong JY, Lin JH, Liu SH, Wan TH. Fireman's job stress: integrating work/ non-work conflict with job demand-control-support model. Eur Rev Appl Psychol 2014;64:83-91.

21. Chang S, Kang H, Kim S, Kim I, Kim J, Kim H. The Development of Korean Emotional Labor Scale and Korean Violence Scale 2013. Seoul: The Korea Occupational Safety and Health Agency, 2014, p.70-73.

22. Chang SJ, Koh SB, Kang D, Kim SA, Kang MG, Lee CG, et al. Developing an occupational stress scale for Korean employees. Korean J Occup Environ Med 2005;17:297-317.

23. Peng J, Li D, Zhang Z, Tian Y, Miao D, Xiao W, et al. How can core selfevaluations influence job burnout? The key roles of organizational com- mitment and job satisfaction. J Health Psychol 2016;21:50-59.

24. Weiss DJ, Dawis RV, England GW. Manual for the Minnesota Satisfaction Questionnaire. Minnesota: Minnesota Studies in Vocational Rehabilitation; 1967.

25. Park IJ. (A)Validation study of the Minnesota Satisfaction Questionnaire (MSQ). Seoul: Seoul University; 2005.

26. Masten AS, Best KM, Garmezy N. Resilience and development: contributions from the study of children who overcome adversity. Dev Psychopathol 1990;2:425-444.

27. Kim JH. Resilience. Goyang: Wisdom House; 2011.

28. Reivich K, Shatté A. The Resilience Factor: 7 Essential Skills for Overcoming Life's Inevitable Obstacles. New York: Broadway Books; 2002.

29. Spitzer RL, Kroenke K, Williams JBW. Validation and utility of a selfreport version of PRIME-MD: The PHQ Primary Care Study. Primary Care Evaluation of Mental Disorders. Patient Health Questionnaire. JAMA 1999;282:1737-1744.

30. Han C, Jo SA, Kwak JH, Pae CU, Steffens D, Jo I, et al. Validation of the Patient Health Questionnaire-9 Korean version in the elderly population: the Ansan Geriatric study. Compr Psychiatry 2008;49:218-223.

31. Spitzer RL, Kroenke K, Williams JB, Löwe B. A brief measure for assessing generalized anxiety disorder: the GAD-7. Arch Int Med 2006;166: 1092-1097.

32. Seo JG, Park SP. Validation of the Generalized Anxiety Disorder-7 (GAD7) and GAD-2 in patients with migraine. J Headache Pain 2015;16:97.

33. Wieclaw J, Agerbo E, Mortensen PB, Bonde JP. Risk of affective and stress related disorders among employees in human service professions. Occup Environ Med 2006;63:314-319.

34. Park SK, Rhee MK, Barak MM. Job stress and mental health among nonregular workers in Korea: What dimensions of job stress are associated with mental health? Arch Environ Occup Health 2016;71:111-118.

35. Aletraris L. How satisfied are they and why? A study of job satisfaction, job rewards, gender and temporary agency workers in Australia. Hum Relat 2010;63:1129-1155.

36. Haddadi P Besharat MA. Resilience, vulnerability and mental health. Procedia Soc Behav Sci 2010;5:639-642.

37. Abbott JA, Klein B, Hamilton C, Rosenthal A. The impact of online resilience training for sales managers on wellbeing and performance. E J Appl Psychol 2009;5:89-95.

38. Grant AM, Curtayne L, Burton G. Executive coaching enhances goal attainment, resilience and workplace well-being: a randomised controlled study. J Posit Psychol 2009;4:396-407.

39. Burton NW, Pakenham KI, Brown WJ. Feasibility and effectiveness of psychosocial resilience training: a pilot study of the READY program. Psychol Health Med 2010;15:266-277.

40. Cho CH, Lee Y. The chronobiologic-based practical approach to shift work. Chronobiol Med 2019;1:103-106. 